\title{
In situ measurements of methane in the troposphere and the stratosphere by the Ultra Light SpEctrometer Amulse
}

\author{
Zineb Miftah El Khair ${ }^{1} \cdot$ Lilian Joly $^{1} \cdot$ Julien Cousin $^{1} \cdot$ Thomas Decarpenterie $^{1} \cdot$ \\ Nicolas Dumelié $^{1} \cdot$ Rabih Maamary $^{1} \cdot$ Nicolas Chauvin $^{1} \cdot$ Georges Durry $^{1}$
}

Received: 11 May 2017 / Accepted: 19 October 2017 / Published online: 13 November 2017

(c) The Author(s) 2017. This article is an open access publication

\begin{abstract}
Methane plays an important role in the radiative balance of the Earth climate: about $20 \%$ of the manmade global warming is related to methane emissions. To contribute to the study of $\mathrm{CH}_{4}$ trends, we have developed a compact lightweight spectrometer $(2.5 \mathrm{~kg})$ by combining an antimonide laser diode at $3.24 \mu \mathrm{m}$ with an $8 \mathrm{~m}$ optical multipass path cell open to the atmosphere. This laser sensor is to be operated from weather balloons to provide with regular in situ methane soundings from ground level up to $\sim 25 \mathrm{~km}$. In this paper, the laser sensor is described as well as the processing of the absorption spectra and the calibration of the instrument. The concentration data obtained from recent stratospheric balloon flights are reported and discussed.
\end{abstract}

Zineb Miftah El Khair

zineb.miftah-el-kha@univ-reims.fr

Lilian Joly

lilian.joly@univ-reims.fr

Julien Cousin

julien.cousin@univ-reims.fr

Thomas Decarpenterie

thomas.decarpenterie@univ-reims.fr

Nicolas Dumelié

nicolas.dumelie@univ-reims.fr

Rabih Maamary

rabih.maamary@univ-reims.fr

Nicolas Chauvin

nicolas.chauvin@univ-reims.fr

Georges Durry

georges.durry@univ-reims.fr

1 Groupe de Spectrométrie Moléculaire et Atmosphérique, Université de Reims-Champagne Ardenne, GSMA, UMR CNRS 7331, Reims, France

\section{Introduction}

Methane is the second most important greenhouse gas released by human activities [1]. Indeed, once in the atmosphere, methane is very efficient in trapping infrared emission, roughly 28 times more efficient than an equivalent amount of carbon dioxide while compared over decadal scales. Methane accounts for roughly $20 \%$ of the manmade global warming that is observed nowadays $[2,3]$. Nonetheless, it seems its role in climate change could be strongly growing [4-7]. Recent study suggests that $\mathrm{CH}_{4}$ concentration is rising faster than at any time during these last 20 years [8]. Particularly in 2014-2015, the methane growing rate was close to $10 \mathrm{ppb}$ year $^{-1}$. The trend in atmospheric $\mathrm{CH}_{4}$ results from the balance between sources (wetlands, lakes, permafrost, agriculture, fossil fuel, biomass burning ...) and sinks (oxidation by atmospheric radicals...). Thus, a better understanding of the global methane budget is needed and the combination of various observational methods is required to figure out which processes predominantly determine the current trends in $\mathrm{CH}_{4}$.

There are a number of ways to quantify the exchange of methane between ecosystems and the atmosphere. Spaceborne remote sensing has been employed for the measurement of methane with large spatial and temporal coverage, using for instance the near -IR or the thermal spectrum of $\mathrm{CH}_{4}$ (for example, the Infrared Atmospheric Sounding Interferometer (IASI) on METEOP-1 satellite or the Tropospheric Emission Spectrometer (TES) on NASA/AQUA $[9-11], \ldots)$. In the coming years, a new MEthane Remote sensing LIdar missioN (Merlin) satellite, will be launched with the objective of tracking potential emission of methane by the permafrost due to global warming. Aircrafts [12, 13], drones as well as ground-based networks [14] have further been used to monitor methane with various techniques 
among which the laser absorption spectroscopy is of particular interest. For at least 25 years, the laser diode spectroscopy has proven extremely useful in providing high temporal resolution, fast response and precise measurements of many key species including methane [15-17]. Furthermore, recent generation of laser diodes, like the antimonide ones, offer an emission wavelength close to 3.3 micron, a spectral region where the strong $v_{3}$ fundamental vibrational band of $\mathrm{CH}_{4}$ lays. It makes it possible to develop highly compact laser diode spectrometers by reducing the required absorption path length. Furthermore, optical fibers are available that allow a convenient modular design of the spectrometer.

The importance of the methane science issue was a strong impetus for us to develop the Amulse balloonborne tunable diode laser spectrometer with the help of the CNES and the CNRS. Amulse is a French acronym for "Atmospheric Measurements by Ultra-Light SpEctrometer". With this project, the strategy consists of delivering numerous regular in situ vertical concentration profiles of $\mathrm{CH}_{4}$ from ground to $\sim 20 \mathrm{~km}$, using weather balloons to be launched by nonspecialists within the framework of atmospheric observational networks. In this paper, we first describe the main design features of Amulse, the data processing as well as the validation tests. Then, we report atmospheric data achieved during recent balloon flights.

\section{Instrumental set up}

\subsection{The Amulse spectrometer}

The principle of the instrument is simple: the laser beam is propagated in the open atmosphere over a few meters; the laser beam is partially absorbed by ambient methane; the $\mathrm{CH}_{4}$ concentration is retrieved from the recording of the amount of absorbed laser energy, using the Beer-Lambert law and an adequate molecular model, in conjunction with in situ atmospheric pressure and temperature measurements. Hence, Amulse uses a laser type ICL DFB diode in a TO5 package emitting at 3.24 micron (purchased from Nanoplus $\mathrm{GmbH}$ ) with an output power around $1.5 \mathrm{~mW}$ for a laser driving current of $165 \mathrm{~mA}$. The laser scans the R(6) transition at $3085.86 \mathrm{~cm}^{-1}$ in the strong $v$ fundamental vibrational band of $\mathrm{CH}_{4}$. To collimate the laser beam down to $2 \mathrm{~mm}$, we use a reflective collimator equipped with a parabolic mirror (2.61-mm focal length). The laser light is then passed to an open-path multipass cell by means of an optical fiberedcollimator. The optical cell, designed in our laboratory, is an Herriott-type one, made of two 2-in. spherical mirrors with a focal length of $150-\mathrm{mm}$ that are separated of nearly $19.5 \mathrm{~cm}$ [18]. The achieved absorption path length is close to $8 \mathrm{~m}$. The cell is operated open to the atmosphere. Nevertheless, the optical cell is protected by a grid to prevent the damages due to the release of ballast during the flight (steel pellets). The cell mirrors are heated to avoid the formation of ice on the mirror surfaces, using $2 \mathrm{~W}$-heaters attached on each mirrors edge. At the output of the optical cell, the laser beam is collected and focused onto a 1-mm diameter InAs photodetector (Judson J12-TE1). The laser driving current is ramped at constant temperature within $\sim 42 \mathrm{~ms}(24 \mathrm{~Hz})$ to scan the $\mathrm{R}(6)$, multiplet of $\mathrm{CH}_{4}$ over a mean spectral range of $0.7 \mathrm{~cm}^{-1}$. By taking into account the average line strengths of this molecular transition $\left(\sim 10^{-19} \mathrm{~cm}^{2} \mathrm{~cm}^{-1}\right.$ molecule $\left.{ }^{-1}\right)$ as well as atmospheric $\mathrm{P}$ and $\mathrm{T}$, the yielded absorption depth ranges from $8 \%$ at ground levels to $4 \%$ at $15 \mathrm{~km}$ and $1 \%$ at $30 \mathrm{~km}$, assuming an $8 \mathrm{~m}$-absorption path length. The strap plug and play spectrometer weighs $2.5 \mathrm{~kg}$ in flight-ready condition, including cabling, thermal insulation and power supplies (ensuring $12 \mathrm{~h}$ of operation). The needed power, 4-10 W which depends on the mirrors heaters, is provided by a +8 VDC Li-Ion battery. The size of the instrument is $33 \times 21 \times 19 \mathrm{~cm}$. The sensor is to be operated in a severe environment in terms of temperature and pressure. Hence great care was taken in the thermal design of the sensor; aluminum and insulation materials combined with heaters are used to maintain an adequate operational temperature inside the mechanical mounting and to avoid electronics and laser drifts (Fig. 1).

The main component of the sensor electronic board is a National Instruments (NI) single board RIO-9636. It is the principal processor used to supervise the satellite communication system (Iridium) as well as to store and acquire the data. The Amulse spectrometer works as a plug-and-play sensor while operated as a piggy-back instrument onboard large scientific gondolas; it was the case for the stratospheric balloon flights reported in this paper. The sensor is turned on just before the balloon launch and the spectra are recorded automatically at $\sim 42 \mathrm{~ms}$-intervals during ascent and descent of the balloon. Detector dark noise is also measured for each spectra during the flight. The data are processed after the recovery of the gondola from the descent under parachutes. 2048 sample points are taken from each in situ absorption spectrum using a 16-bit digitizer (the digitalization is ensured by the NI single board RIO-9636). The digitized spectra are then stored into a SDHC memory card and processed after the flight.

The atmospheric pressure and temperature are monitored by International Met Systems "iMET-1-RS" radiosondes integrated in Amulse. The temperature accuracy given by the head thermistor is equal to $0.2{ }^{\circ} \mathrm{C}$; the pressure accuracy given by the piezo-resistive sensor is equal to $0.5 \mathrm{mbar}$. These $\mathrm{P}$ and $\mathrm{T}$ sensors are widely used by the meteorologists for the atmospheric sounding of the middle atmosphere. The location of the sensor in flight is obtained from the iMET-1 onboard GPS. While operated under weather balloon, the Amulse sensor is equipped with a separation 


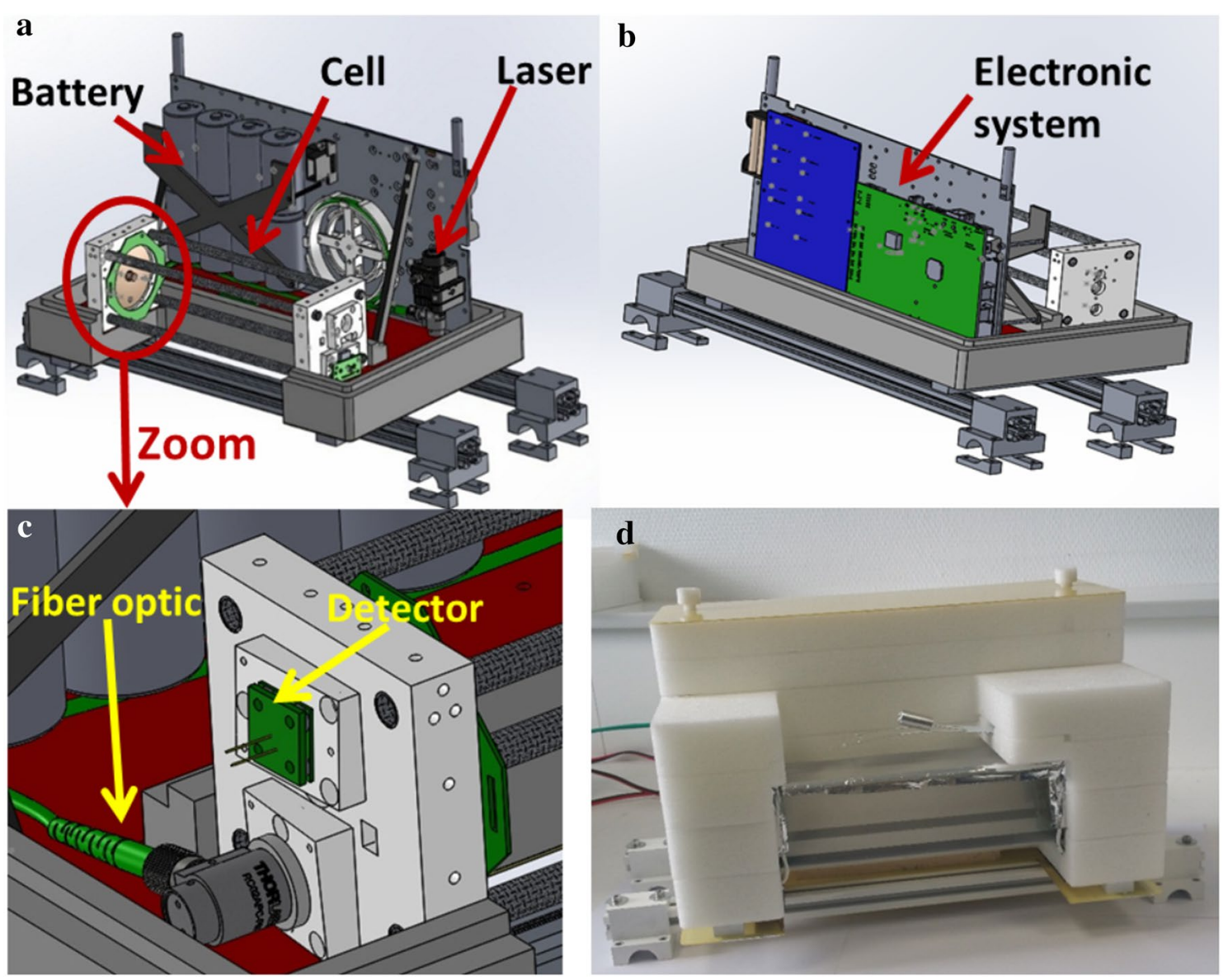

Fig. 1 a-c 3D schematics of the Amulse sensor $\mathbf{c}$ is a zoom on the optical fiber connection to the input cell mirror, $\mathbf{d}$ is a picture of the ready-toflight Amulse sensor

system (supervised by the NI RIO-9636) used to release the instrument from the weather balloon. In this configuration, a few data such as instrument location are transmitted to the ground through the Iridium telemetry. Given that the molecular absorption depths range from 8 to $1 \%$ during a flight, we have chosen a simple direct detection technique with no modulation of the laser current or of the laser beam. Combined with a 16-digit digitalization system, this technique was proven to be well-adapted to the in situ sensing of the middle atmosphere [19] for absorption depth over $1 \%$. Figure 2 displays a principle schematics of Amulse.

\subsection{Data processing}

While propagating in the open optical cell, the laser beam is partially absorbed by ambient atmospheric methane. The absorbed amount of laser energy is determined using the Beer-Lambert law:

$\tau(\sigma)=I(\sigma) / I_{0}=\mathrm{e}^{-k(\sigma) L}$,

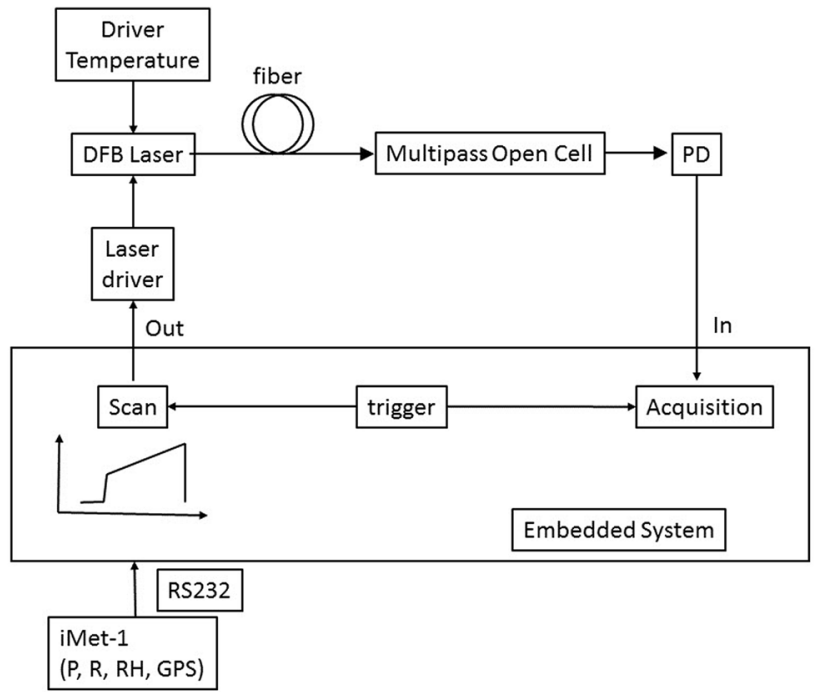

Fig. 2 Communication principle between the NI RIO-9636 and the other compounds of Amulse (laser, detector, cell...) 
where $\tau(\sigma)$ is the transmission at the wavenumber $\sigma, I_{0}$ is the incident intensity of the probe beam, $I$ is the intensity at the wavenumber $\sigma$ observed after propagation through a length $L$ of the absorbing medium, and $k(\sigma)$ is the spectral absorption coefficient. The absorption coefficient may be described as:

$k(\sigma)=\rho \cdot N \cdot S\left(T, \sigma_{0}\right) \cdot \Phi\left(\sigma-\sigma_{0}\right)$,

where $\rho$ is the mixing ratio of the absorbing species, $N$ is the number density, $S\left(T, \sigma_{0}\right)$ is the temperature-dependent transition line strength [20] centered at $\sigma_{0}$, and $\Phi\left(\sigma-\sigma_{0}\right)$ is the line-shape function [21-23]. $\sigma_{0}$ is the position of the molecular transition.

The spectroscopy associated with the $\mathrm{R}(6), v_{3}$ methane multiplet swept over by the laser, was revisited in our laboratory including the temperature dependences of the pressure-broadening, Dicke and line mixing coefficients. The used molecular model that takes into account line-mixing effect between some transitions of the selected multiplet is described in Ref. [24]. The concentration retrieval technique (Fig. 3) consists of a non-linear least-squares fit over the full experimental molecular line shape in conjunction with the $P$ and $T$ in situ measurements. In a first step, the baseline $\left(I_{0}\right)$ is determined from a third-degree polynomial interpolation over zero-absorption regions on both side of the spectrum (Fig. 3b) to extract the molecular transmission $T(\sigma)$ (Fig. 3c).
The wavenumber scale is constructed by determining the positions of the main spectral features, i.e. the peaks of the two major transitions (see Fig. 3c). A non-linear leastsquares fit (Fig. 3d) is then applied to the full molecular line shape to retrieve the methane concentration by means of the molecular model described above and by using the $P$ and $T$ in situ measurements yielded by the onboard sensors. The residuals observed in (Fig. 3d) are obtained by taking the difference between the fitted transmission (red line) and the experimental transmission (black line).

Fitting the molecular line shape involves many procedures that contribute to the overall precision error: estimation of the base line, wavelength calibration and correction of the laser nonlinearities, detector dark-current subtraction, and precision error in monitoring the in situ pressures and temperatures. Taking into account the signal-to-noise ratio achieved in the spectra and all the other sources of error that are due to the retrieval process, the mixing ratios are determined within a few percent for a measurement time of $\sim 42 \mathrm{~ms}$. The precision error is of $1 \%$ at low altitudes (in the troposphere) and of $4 \%$ at high altitudes (in the stratosphere). The precision error can further be improved by coaddition of successive elementary concentration measurements at the cost of a lower spatial resolution in the vertical concentration profile.
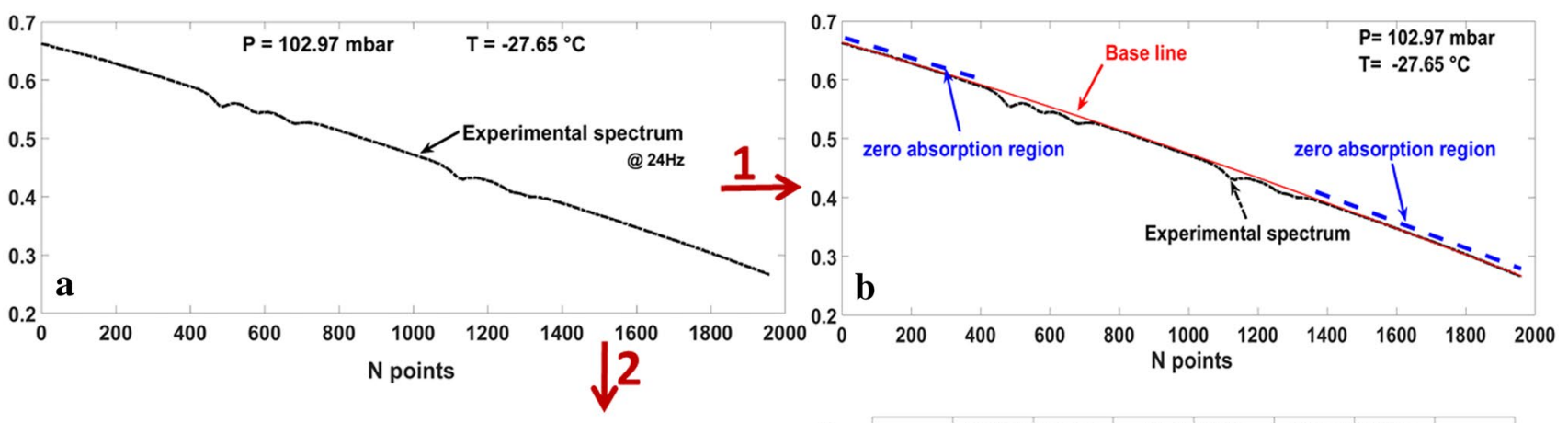

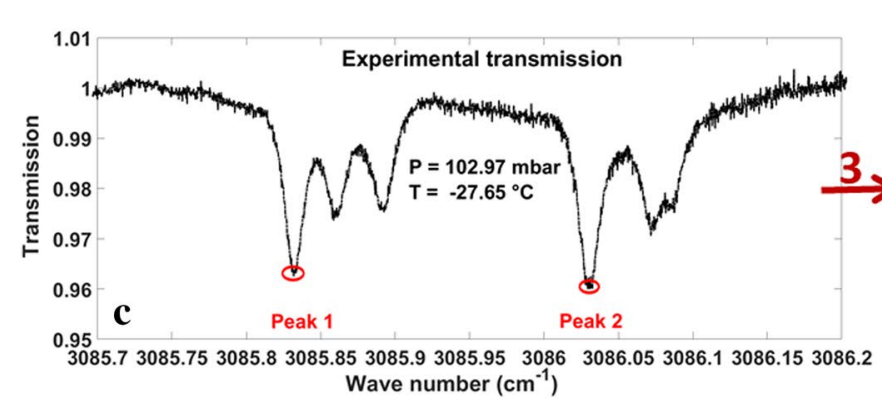

Wave number $\left(\mathrm{cm}^{-1}\right)$

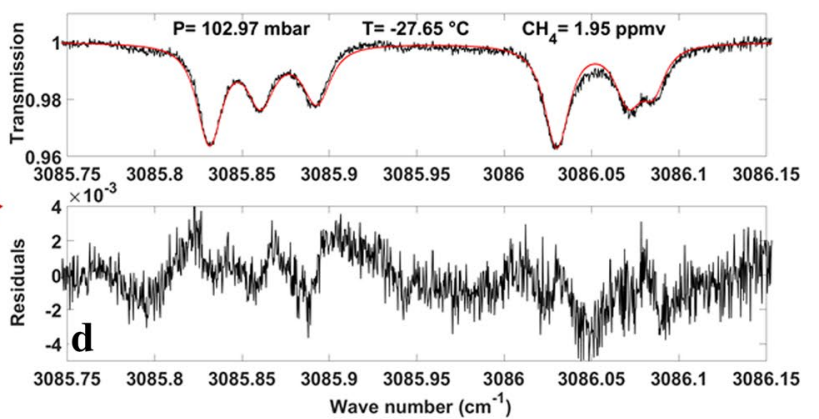

mission extracted from the spectrum using the baseline. The peaks of the two major transitions at 3085.83 and $3086.03 \mathrm{~cm}^{-1}$, that are used to construct the wavenumber scale, are featured, $\mathbf{d}$ the experimental $\mathrm{CH}_{4}$ transmission (black line), the fitted $\mathrm{CH}_{4}$ transmission (red line) as well as the residuals from the non-linear least-squares fit are displayed. See text for more details 


\section{Test of Amulse in the SIMEON facility}

As the instrument is to be operated in a severe atmospheric environment in terms of pressure and temperature, we have tested the behavior and the performances of Amulse using the SIMEON (French acronym for "SIMulateur Environnement Operationnel Nacelle") facility (Fig. 4) of the French Space Agency. This installation made it possible to reproduce the conditions encountered during a stratospheric flight. Harsh environmental conditions may impact the sensor performances by causing, for instance, a misadjustment of the optical cell, a thermal drift of the electronics, a spectral drift of the laser emission wavelength ...

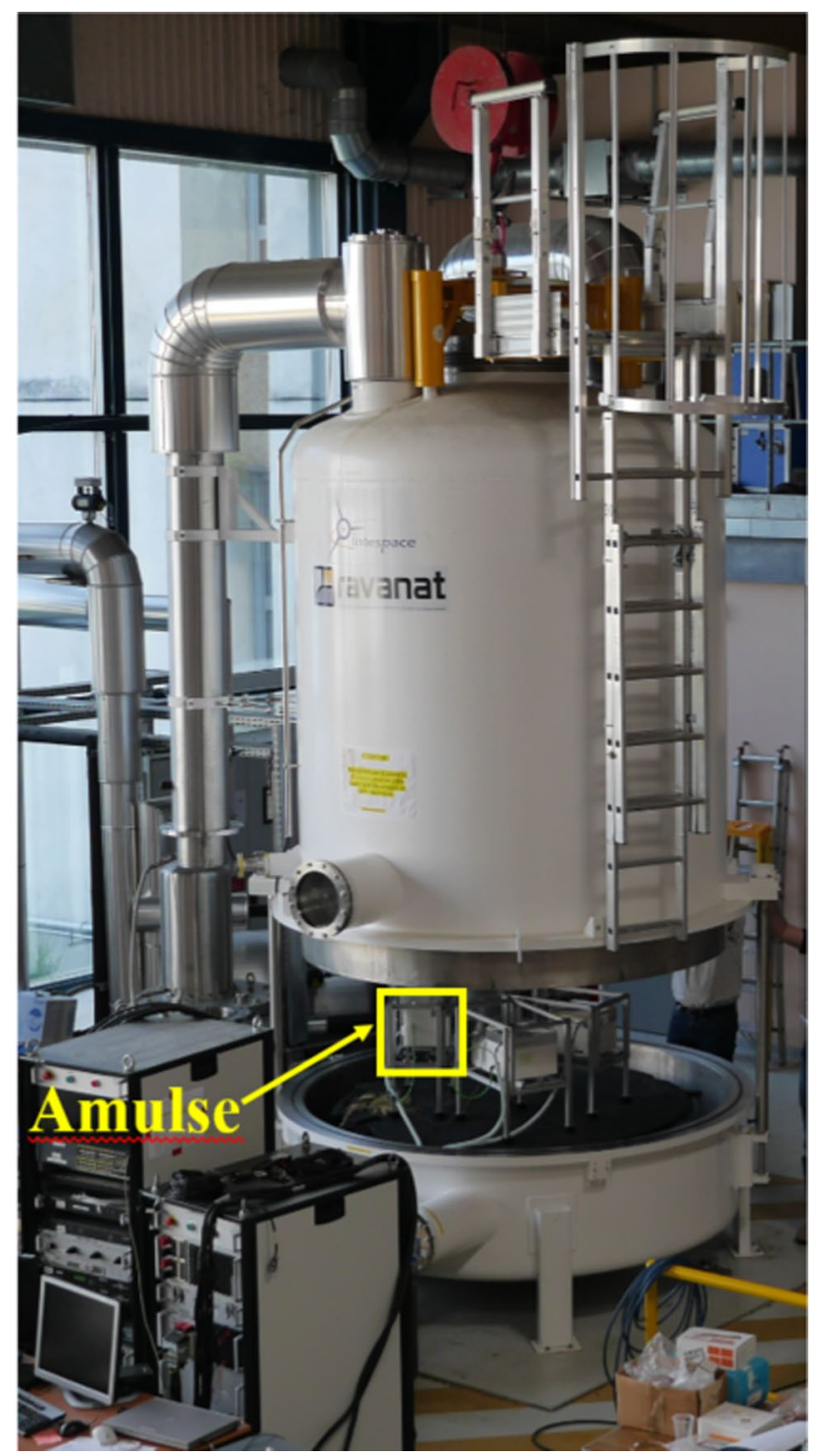

Fig. 4 Picture of SIMEON (French acronym for "SIMulateur Environnement Operationnel Nacelle"). Amulse was located inside a big metallic cell and tested at low pressure and temperature using calibrated methane samples. See text for more details
The instrument was located in a large metallic cell as shown in Fig. 4 that was filled up with a mixing of dry air and calibrated methane samples $(\sim 2006.0 \pm 0.2$ and $1925.0 \pm 0.2 \mathrm{ppb}$ ) provided by LSCE laboratory in Saclay, France. A few thousands of in situ methane spectra were then recorded at various pressures and temperatures during several hours. Figure 5 reports several spectra achieved with the Amulse in the SIMEON cell for a pressure range corresponding to a flight from ground levels up to $20 \mathrm{~km}$. The spectra were processed using the procedure described above to retrieve the methane concentration.

Basically the signal-to-noise ratio achieved in the spectra, even for the lowest pressure, was found in compliance with our science objectives. Nevertheless, a perturbating Fabry-Perot fringing [25] process was observed for some conditions of low temperature and pressure. This problem is probably due to the coupling of the laser with the optical fiber. However, the problem has been solved after the Simeon test by using a coupling lens with an adapted antireflection coating. Nonetheless, the Simeon campaign confirmed the overall smooth-working of the Amulse sensor in harsh $P, T$ conditions: no electronics, laser drift or major optical mis-adjustment were observed. Table 1 gives the results obtained for several series of measurements at different pressures and temperatures using a calibrated methane sample at 2005 ppmv. A second set of measurements was achieved with a $\mathrm{CH}_{4}$ sample at 1925 ppmv. Figure 6 reports the yielded data for both $\mathrm{CH}_{4}$ calibrated samples. During the Simeon test, we have had to cope with a problem of dilution: indeed, it was impossible to achieve a deep vacuum in the large cell, so the remaining air degraded the accuracy when probing low pressure samples (below $100 \mathrm{hPa}$ ). Hence, as can be seen in Table 1 and in Fig. 6, the difference between the retrieved $\mathrm{CH}_{4}$ mixing ratio and the mixing ratio of the calibrated gas sample ranges from 0.2 to $4 \%$. The largest discrepancies are observed at low pressures, which are mostly due to the perturbating dilution effect mentioned above. The decrease in the signal-to-noise ratio must also be taken into account at low pressures (see Fig. 5). At high pressure, above $200 \mathrm{hPa}$, the observed inaccuracy is of less than $1 \%$. Globally, the behavior of the instrument as well as its performance was found rather in good compliance with our objectives of atmospheric probing.

Various sets of retrieved methane concentrations obtained during SIMEON were further used to calculate Allan standard deviations $[26,27]$ to determine the optimized integration time, taking into account the various sources of noise and the instabilities inherent to the instrument. The Allan standard deviations were determined for four sets of data at different $P$ and $T$ in the Simeon cell. The combination between $P, T$ and the methane mixing ratio allowed us to simulate the conditions encountered by the instrument at different altitudes to figure out whether the integration time 
Fig. 5 In situ methane transmission at different pressures and temperatures achieved during the Simeon test in Toulouse, France. The measurement time is $\sim 42 \mathrm{~ms}$. The experimental as well as the fitted transmission (solid red line) is reported. See text for more details
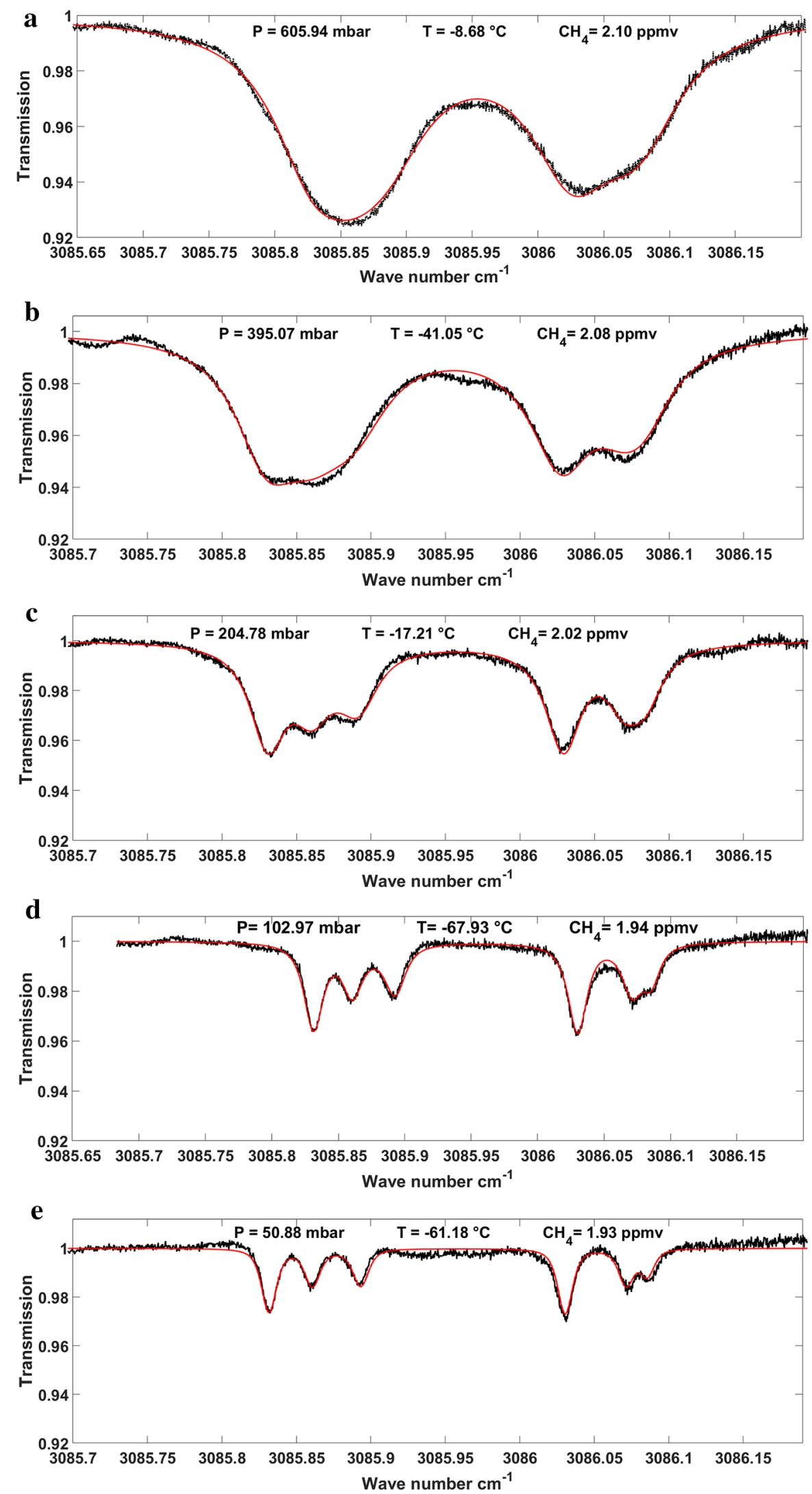
Table 1 The methane concentrations measured during the SIMEON campaign

\begin{tabular}{llllll}
\hline Altitude $(\mathrm{km})$ & $P(\mathrm{mbar})$ & $T\left({ }^{\circ} \mathrm{C}\right)$ & $\rho_{\mathrm{CH} 4}(\mathrm{ppmv})$ & $\sigma_{\mathrm{CH} 4}(\mathrm{ppmv})$ & $\begin{array}{l}\rho_{\text {sample }}-\rho_{\mathrm{CH} 4 \mathrm{p}} \\
(\%)\end{array}$ \\
\hline 26 & 23.15 & -28.04 & 1.93 & 0.06 & 4 \\
21 & 50.35 & -61.86 & 1.93 & 0.02 & 4 \\
17 & 102.49 & -68.43 & 1.94 & 0.09 & 3 \\
12 & 204.37 & -17.71 & 1.99 & 0.02 & 1 \\
8 & 389.44 & -31.88 & 2.00 & 0.01 & 0.3 \\
5 & 605.24 & -9.17 & 2.01 & 0.03 & 0.2 \\
3 & 731.99 & -1.29 & 2.00 & 0.02 & 0.3 \\
\hline
\end{tabular}

A concentration point results from the co-addition of thousands of elementary concentration values. The mean value as well as the standard deviation is given in columns 3 and 4 . The last column gives the difference between the retrieved mean concentration and the exact sample concentration

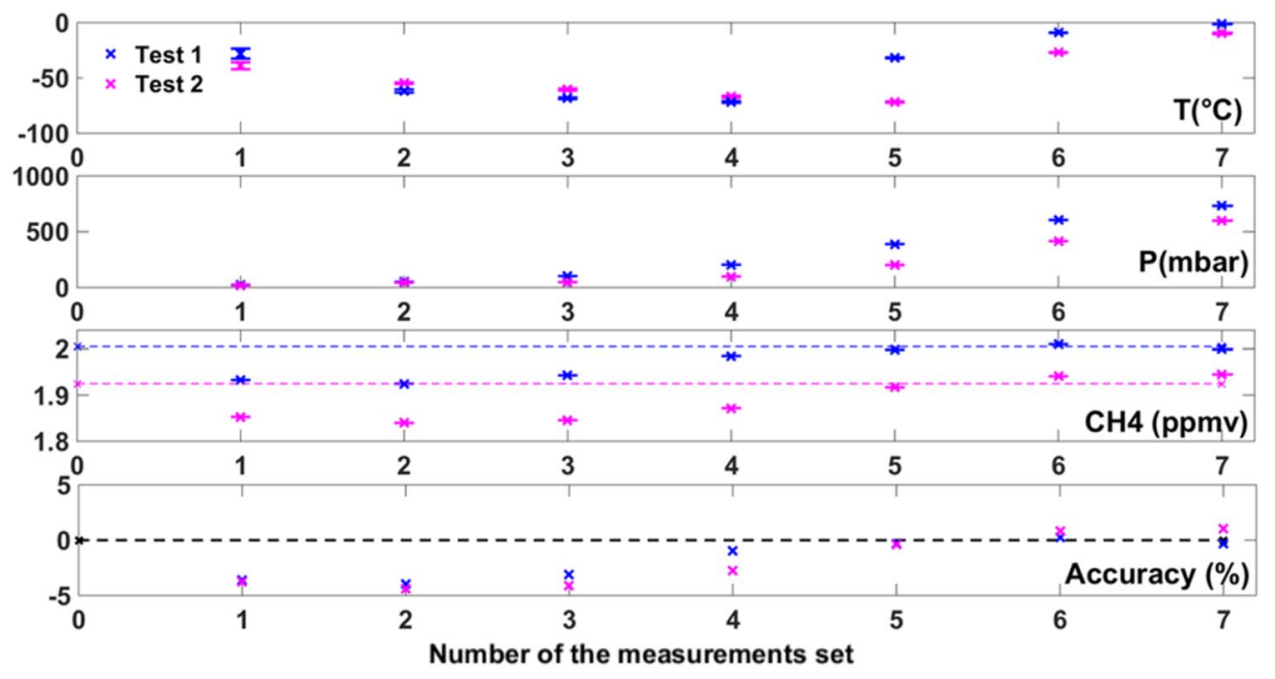

Fig. 6 Experimental methane concentration measurements achieved during the Simeon test campaign. Panel (1) and (2) give the $T$ and $P$ values for both sets of measurements, i.e. for a methane sample at $2006 \mathrm{ppm}$ (in blue) and a methane sample at $1.925 \mathrm{ppm}$ (in red). Panel (3) gives the methane concentration for each $T$ and $P$. A point

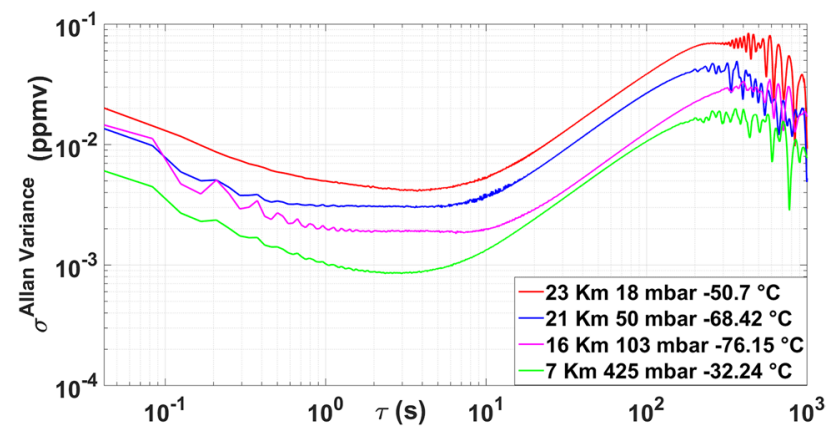

Fig. 7 Allan standard deviation plot in logarithmic scale for four different pressures and temperatures. See text for more details

is to be adapted according to altitude. In Fig. 7, the Allan standard deviation are plotted against the integration time on a logarithmic scale. in panel (3) concentration $p$ is a mean value yielded by processing thousand elementary spectra. Panel (4) gives the accuracy (i.e. the difference in percentage between the value of the methane bottle and the restituted experimental value). See text for more details

First a quasi-linear decay is observed for each case, giving insight upon a decrease in the data deviation with increasing integration time. This is the theoretical behavior expected for a drift-free system containing only white noise. Then, for integration time over roughly a few seconds (the optimum measurement time), the inherent instabilities of the instrument counterbalance the reduction of the white noise achieved by increasing the integration time and the Allan standard deviations increase again. Table 2 resumes the conclusion from the Allan standard deviation calculations, in terms of pressure and temperature and in terms of optimization of the integration time. Note that the optimum integration time is almost the same for the four cases. It means that we can select one optimized integration time that is suitable over a complete stratospheric flight. However, $\sigma_{\text {Allan }}$, the value of the Allan standard deviation at the optimized integration 
Table 2 Allan standard deviation calculations at various $\mathrm{P}$ and $\mathrm{T}$

\begin{tabular}{llll}
\hline $\mathrm{P}(\mathrm{mbar})$ & $T\left({ }^{\circ} \mathrm{C}\right)$ & $\tau_{\text {Allan }}(\mathrm{s})$ & $\sigma_{\text {Allan }}(\mathrm{ppmv})$ \\
\hline 427 & -32.2 & 2 & $8.50 \mathrm{E}-04$ \\
103 & -76.2 & 3 & $1.80 \mathrm{E}-03$ \\
50 & -68.4 & 2 & $3.00 \mathrm{E}-03$ \\
18 & -50.7 & 3 & $4.10 \mathrm{E}-03$ \\
\hline
\end{tabular}

The third column gives the optimized integration time, i.e. the time at which the Allan standard deviation is minimum. For each optimized integration time, the fourth column gives the corresponding value of the Allan standard deviation

time, changes with pressure and temperature. This could be related to the decreasing signal-to-noise ratio in the spectra that becomes the predominant limitation at low pressures. This point is still under investigation.

The calibration is made in the laboratory a few days before each balloon campaign. In particular, we regularly check out that there is no spectral drift in the laser emission wavelength (aging of the laser diode). The laser sensor revealed to be very robust during field operations and it requires only preventive calibration in the laboratory. It is not needed to calibrate the instrument right on the launching site or just before the flight.

\section{In situ validation test}

In situ measurements of $\mathrm{CH}_{4}$ were made using a Picarro CRDS (for Cavity Ring-Down Spectroscopy) CO/ $\mathrm{CO}_{2} / \mathrm{CH}_{4} /$ $\mathrm{H}_{2} \mathrm{O}$ analyzer (model G1301, Picarro Inc.) [28] and Amulse, side by side, in a closed hangar. After being calibrated, the analyzer pulled air from a wing-mounted inlet continuously at a few centimeters from the AMULSE multipass cell for about $6000 \mathrm{~s}$. Measurements from both instruments were averaged for 5 s. Full Picarro measurement (Fig. 8a, red line) shows a good agreement with the AMULSE measurements (black line) over all the concentration range with a mean residual of $0.02 \mathrm{ppmv}$. The standard deviation of the residual is equal to $0.08 \mathrm{ppmv}$. Figure $8 \mathrm{~b}$ shows the linear correlation between the two instruments. The red line is the linear regression with $Y=1.0093 X+0.0036$. Since (a) and (b) of the equation above are closed to 1 and 0 respectively and $R^{2}=0.9904$, we can conclude that there is a great agreement between both measurements.

\section{Flight results}

The Amulse sensor was first test flown on August 2015 during the "Stratoscience" in Timmins, Canada $\left(48^{\circ} \mathrm{N}\right)$. This flight was followed by a second one on 31 August 2016 during the KASA campaign that took place in Kiruna, in

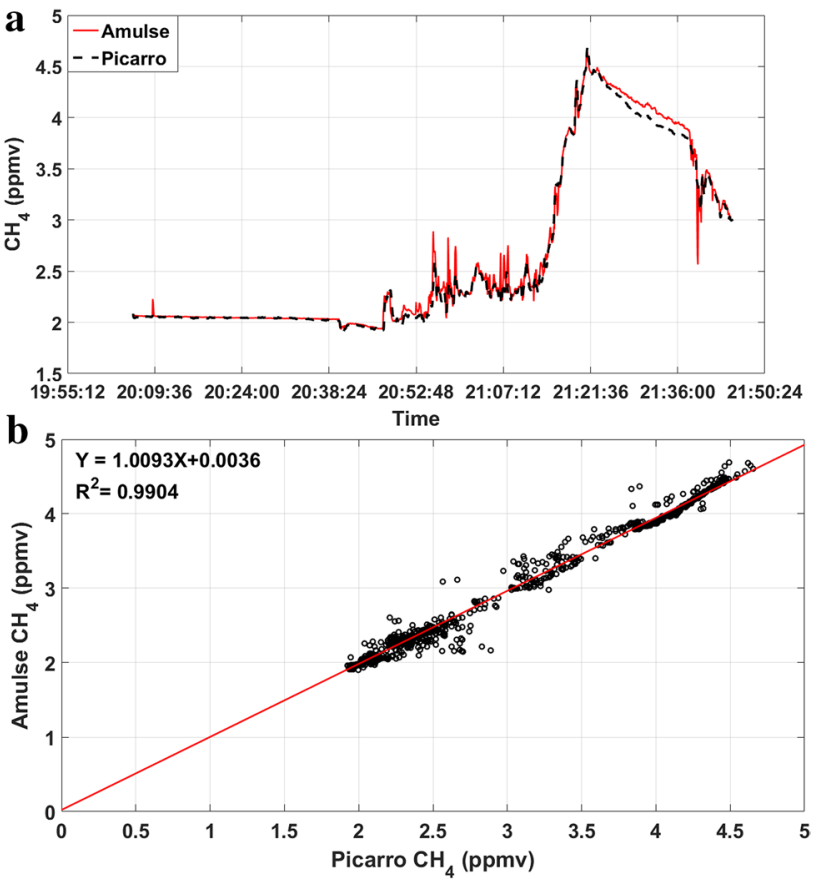

Fig. 8 a Picarro vs. Amulse $\mathrm{CH}_{4}$ intercomparaison. On the upper panel Picarro's data are plotted in red (continuous line) while Amulse's data are in black (discontinuous line). b The correlation between the Amulse and Picarro's measurements

northern Sweden $\left(67^{\circ} \mathrm{N}\right)$. For both flights, the instrument was installed as a piggy-back onboard a large scientific gondola (Fig. 9) devoted to the in situ measurements of greenhouse gases in the middle atmosphere.

An open stratospheric balloon operated by the CNES and inflated with $150,000 \mathrm{~m}^{3}$ of He was used for both flights to reach a float altitude close to $34 \mathrm{~km}$. The total duration of the flight was of $8 \mathrm{~h}$ in Canada 2015 and $5 \mathrm{~h}$ in Kiruna 2016. The Amulse sensor was turned on a few minutes before the launch and was operated automatically. The data were recovered from the onboard memory card after the landing under parachutes of the gondola. The data were taken at a few milliseconds intervals during ascent and descent of the balloon. Roughly thousands of in situ methane absorption spectra were recorded. The data yielded by Amulse during the ascent were of better quality, probably due to a degradation of the mirror surfaces during the second part of the flight. Hence, for the spectra recorded during the descent a pertubating Fabry-Perot fringing degraded the signal-tonoise ratio. We suspect two main reasons; the speed descent is higher once the system is operated under parachutes which could cause turbulences inside the open optical cell; the mirror surfaces could degrade with time over a few-hours-flight in a severe atmospheric environment, which could cause a lowering of the signal-to-noise ratio in the spectra at the end of the flight. This phenomenon was observed in both cases, in Canada as well as in Sweden. Figure 10 shows several 


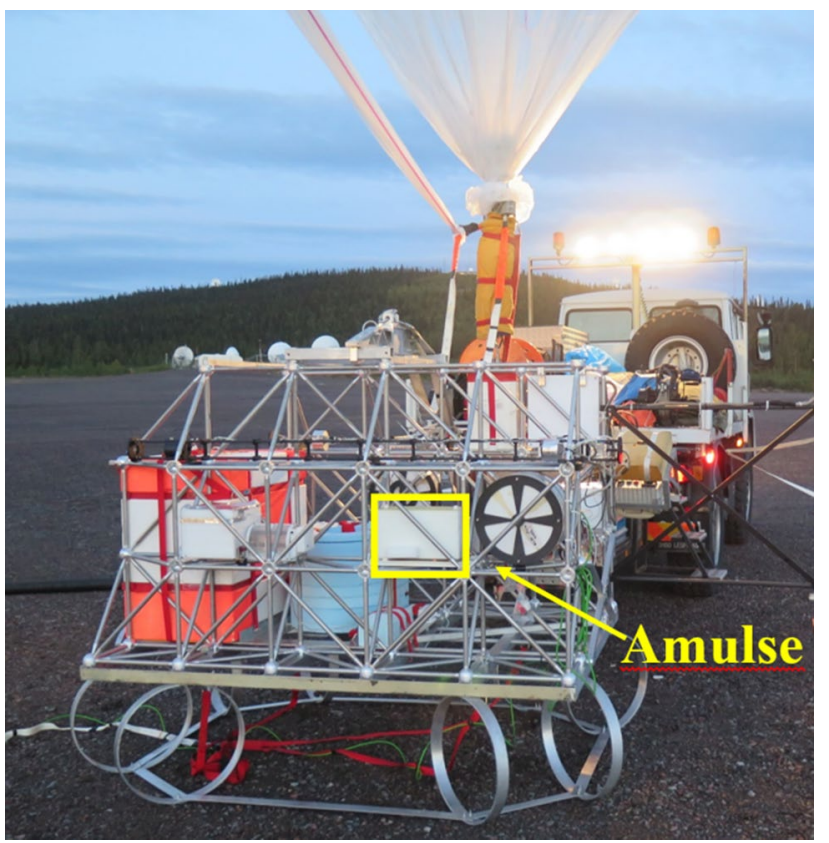

Fig. 9 A picture of the scientific gondola ready to be launched in Kiruna, Sweden, in August 2016, with the Amulse sensor installed onboard

spectra recorded during the ascent in Kiruna for an altitude ranging from ground level to $25 \mathrm{~km}$. The measurement time for each individual spectrum is of $\sim 42 \mathrm{~ms}$.
The spectra were processed using the methodology described above. Figure 11 displays the result of a fit applied to one spectrum recorded at $19 \mathrm{~km}$.

The Figs. 12 and 13 shows the vertical concentration profile yielded by Amulse in Kiruna 2016 and Canada 2015 respectively.

Both vertical concentration profiles are found in agreement with the expected overall shape of a methane vertical profile in the troposphere (altitudes $<\sim 15 \mathrm{~km}$ ) and in the lower stratosphere, at mid- and high-latitudes respectively (in Canada and in northern Sweden, respectively). In the troposphere, the $\mathrm{CH} 4$ mixing ratio is found almost constant, ranging between 1.8 and 1.9 ppmv. At higher altitudes, above the tropopause, the methane mixing ratio decreases due to chemical oxidation processes occurring in the stratosphere, reaching a value close to $\sim 1 \mathrm{ppmv}$ at $25 \mathrm{~km}$. A deeper analysis of the vertical concentration profiles, in conjunction with the various measurements provided by the other instruments onboard the scientific gondola as well as in conjunction with satellite observations and by using atmospheric modelling, is currently underway and will be published apart.

\section{Conclusion}

We have reported the development of a lightweight $(<2.5 \mathrm{~kg})$ balloonborne near-infrared diode laser spectrometer devoted to the in situ monitoring of $\mathrm{CH}_{4}$ from weather

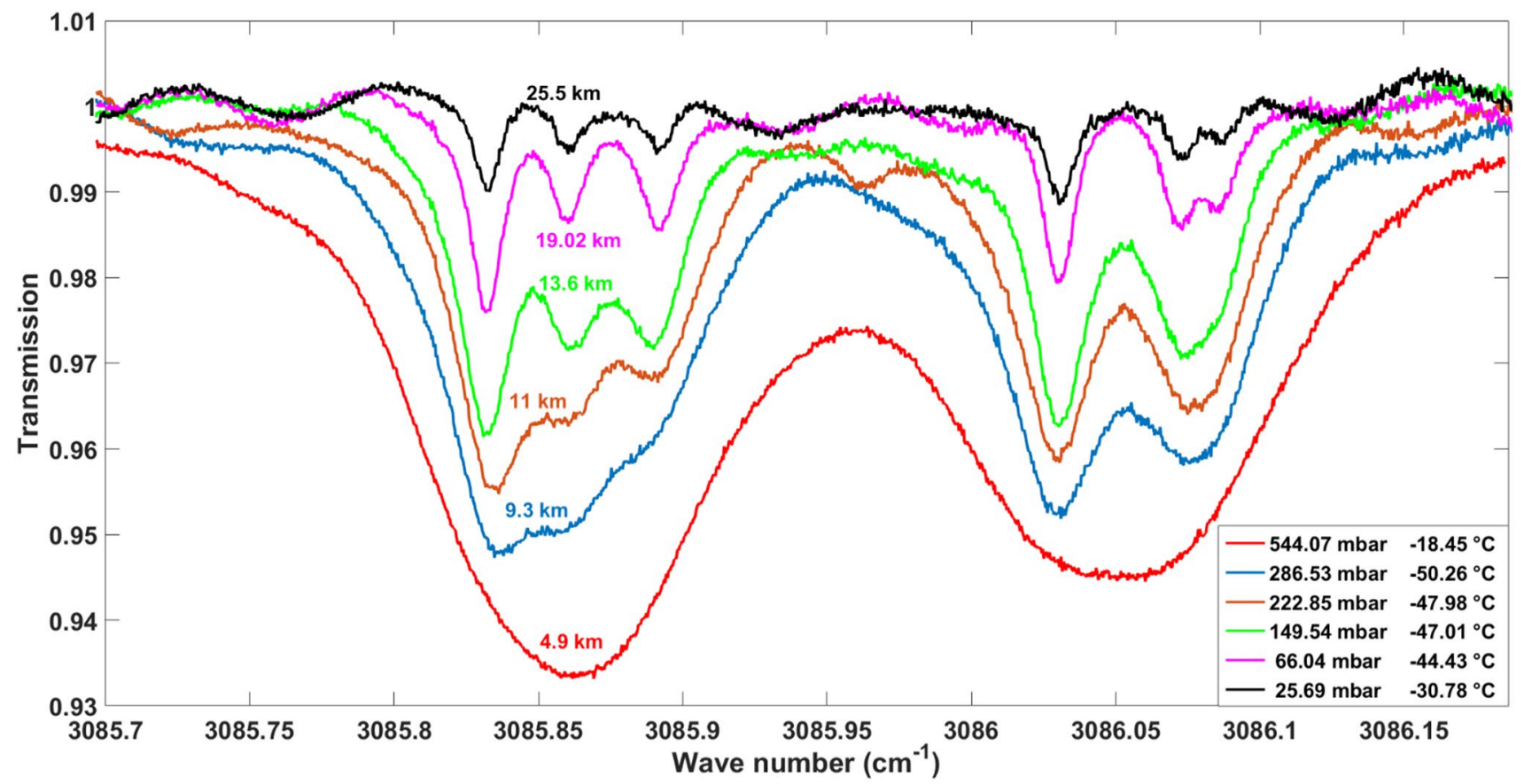

Fig. 10 In situ spectra yielded by Amulse sensor in Kiruna $\left(67^{\circ} \mathrm{N}\right)$ at various altitudes in the troposphere and the stratosphere during the flight campaign. The spectra are recorded in $\sim 42 \mathrm{~ms}$ 


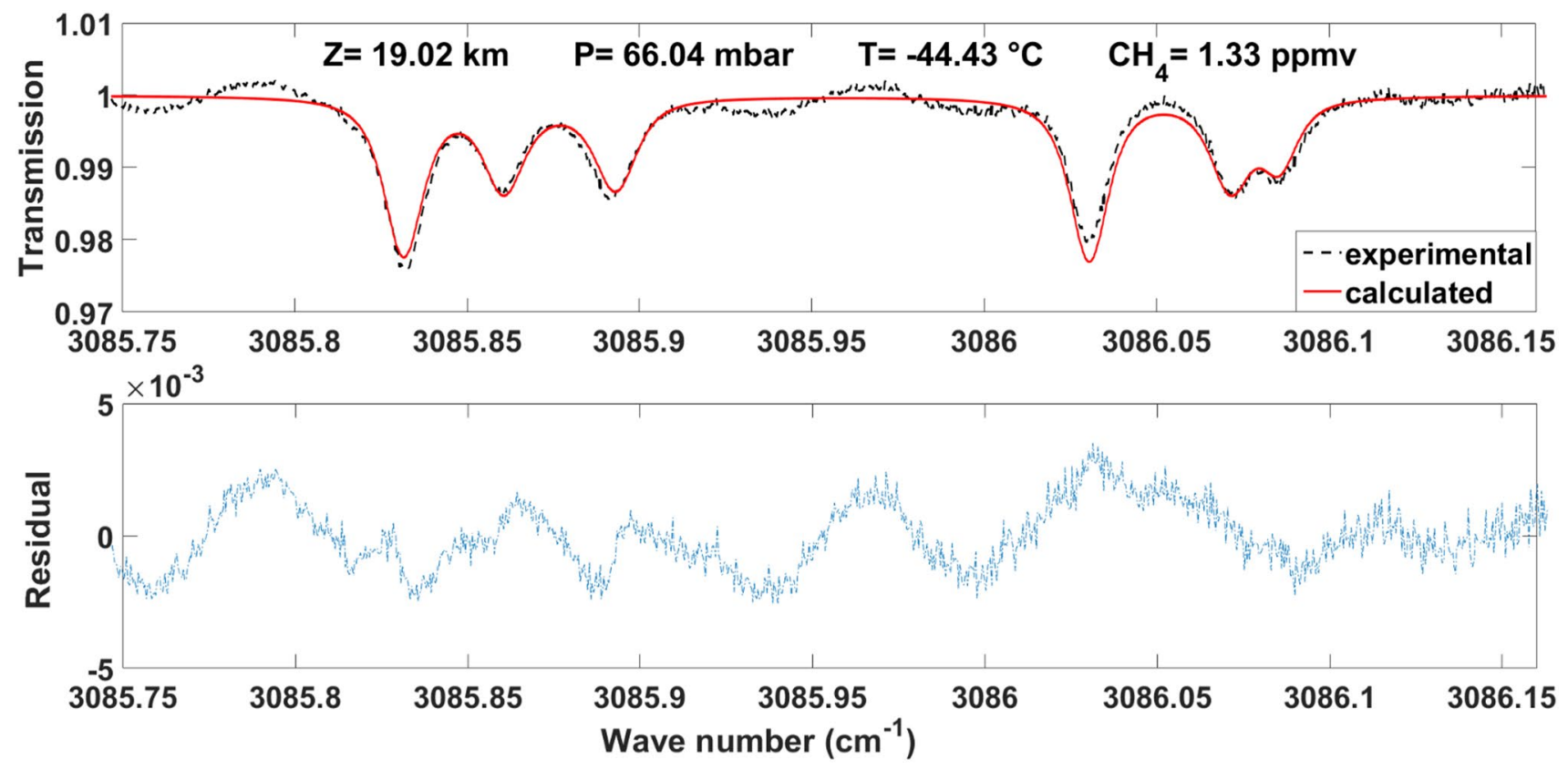

Fig. 11 An in situ $\mathrm{CH} 4$ spectrum recorded at $19 \mathrm{~km}$ by the Amulse sensor during the campaign flight in Kiruna, Sweden, in August 2016. The simulated spectra (continuous line) achieved by fitting the full molecular line shapes using Hitran spectroscopic and parameters

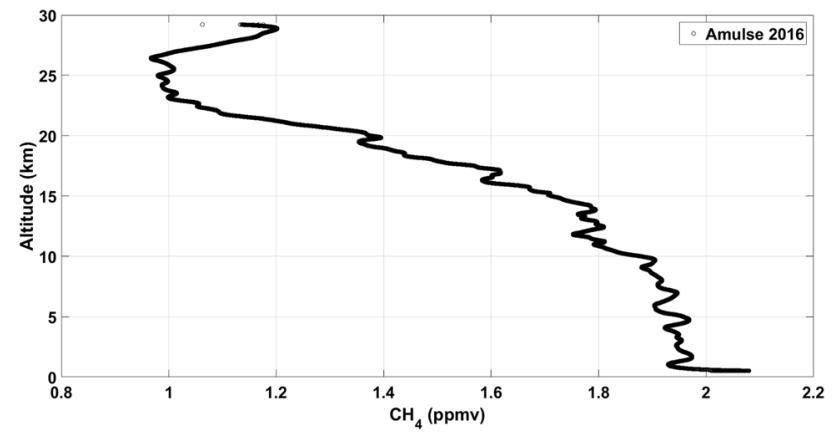

Fig. 12 Methane vertical concentration profile in the upper troposphere and the lower stratosphere obtained by the Amulse sensor (in Sweden 2016) within the KASA flight campaign. See text for more details

balloons. The instrument was successfully flight-tested in the stratosphere using an open stratospheric balloon. The Amulse was found easy to deploy as it worked automatically in a plug-and-play mode. The achieved accuracy laid within a few percent for an elementary measurement time of less than $50 \mathrm{~ms}$. The instrument was operated continuously during $12 \mathrm{~h}$ in the middle atmosphere and worked flawlessly despite the severe environment.

The light weight $(<2.5 \mathrm{~kg})$ of Amulse does match the flight certification required from a sensor to be flown under weather balloon: hence, a campaign with weather balloons is further planned in 2017 with the support of Meteo-France, data in [15] in conjunction with the in situ $\mathrm{P}$ and $\mathrm{T}$ measurements is superimposed to the experimental spectra (discontinuous line). The lower panel displays the residuals of the fit which are lower than $10^{-3} \mathrm{ppm}$

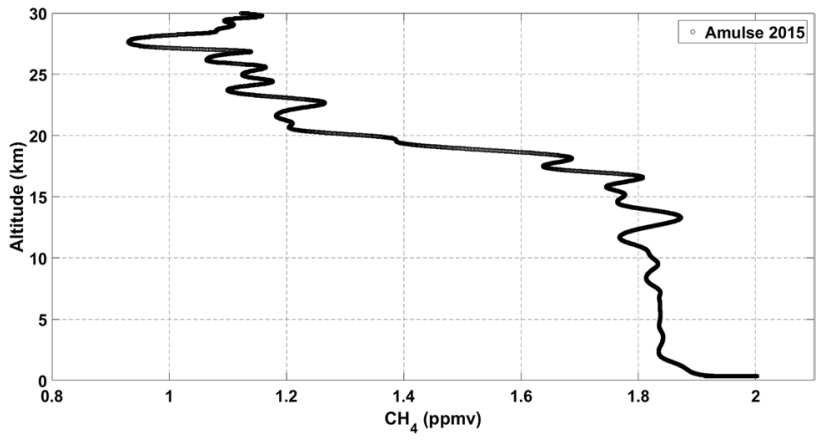

Fig. 13 Methane vertical concentration profile in the upper troposphere and the lower stratosphere obtained by the Amulse sensor in Canada 2015

the French meteorological institute. The Amulse sensor will be operated from $3 \mathrm{~m}^{3}$ balloons to reach a ceiling altitude close to $30 \mathrm{~km}$. Furthermore, an upgrade of Amulse is currently underway that consists of adding a second channel devoted to the in situ measurement of $\mathrm{CO}_{2}$ by laser spectroscopy at 2.04 micron. The challenge consists of providing a simultaneous measurement of $\mathrm{CH}_{4}$ and $\mathrm{CO}_{2}$, while maintaining the overall weight of the dual-gas sensor below $2.5 \mathrm{~kg}$.

Acknowledgements We are deeply grateful to Dr. Cyril Crevoisier and his team for the Picarro data. We further thank the CNES, the French space agency, and the Technical Department of the INSUCNRS for the management of the balloon operations. 
Open Access This article is distributed under the terms of the Creative Commons Attribution 4.0 International License (http://creativecommons.org/licenses/by/4.0/), which permits unrestricted use, distribution, and reproduction in any medium, provided you give appropriate credit to the original author(s) and the source, provide a link to the Creative Commons license, and indicate if changes were made.

\section{References}

1. S.A. Pegov, Global ecologylmethane in the atmosphere (Elsevier, Amsterdam, 2010)

2. D.A. Lashof, D.R. Ahuja, Relative contributions of greenhouse gas emissions to global warming. Nature 344, 529-531 (1990). (Letters to nature)

3. E. Dlugokenscky, S. Houweling, Chemistry of the atmospherelMethane, Encyclopedia of Atmospheric Sciences, (Elsevier, Amsterdam, 2015), pp. 363-371

4. D.T. Shindell, V. Grewe, Separating the influence of halogen and climate changes on ozone recovery in the upper stratosphere. J. Geophys. Res. 107(D12), 4144 (2002)

5. H.H. Chang, H. Hao, S.E. Sarnat, A statistical modeling framework for projecting future ambient ozone and its health impact due to climate change. Atmos. Environ. 89, 290-297 (2014)

6. I.S.A. Isaksen, C. Granier, G. Myhre, T.K. Berntsen, S.B. Dalsoren, M. Gauss, Z. Klimont, R. Benestad, P. Bousquet, W. Collins, T. Cox, V. Eyring, D. Fowler, S. Fuzzi, P. Jockel, P. Laj, U. Lohmann, M. Maione, P. Monks, A.S.H. Prevot, F. Raes, A. Richter, B. Rognerud, M. Schulz, D. Shindell, D.S. Stevenson, T. Storelvmo, W.-C. Wang, Atmosphéric composition change: climate-Chemestry interactions. Atmos. Environ. 43, 5138-5192 (2009)

7. G.A. Schmidt, D.T Drew, Atmospheric composition, radiative forcing, and climate change as a consequence of massive methane release from gas hydrates. Paleoceanography 18(1) (2003)

8. M. Saunois, R.B. Jackson, P. Bousquet, B. Poulter, J.G. Canadell, The growing role of methane in anthropogenic climate change. Environ. Res. Lett. 11, 120207 (2016)

9. C. Crevoisier, D. Nobileau, A.M. Fiore, R. Armante, A. Chédin, N.A. Scott, A new insight on tropospheric methane in the Tropics-first year from IASI hyperspectral infrared observations. Atmos. Chem. Phys. 9, 6855-6887 (2009)

10. A. Razavi, C. Clerbaux, C. Wespes, L. Clarisse, D. Hurtmans, S. Payan, C. Camy-Peyret, P.F. Coheur, Characterization of methane retrievals from the IASI space-borne sounder. Atmos. Chem. Phys. 9, 7889-7899 (2009)

11. H.H. Aumann, M.T. Chahine, C. Gautier, M.D. Goldberg, E. Kalnay, L.M. McMillin, H. Revercomb, P.W. Rosenkranz, W.L. Smith, D.H. Staelin, L.L. Strow, J. Susskind, AIRS/AMSU/HSB on the aqua mission: design science objectives, data products, and processing systems. IEEE Trans. Geosci. Remote Sens. 41(2), 253-264 (2003)

12. D.J. Jacob, J.H. Crawford, H. Maring, A.D. Clarke, J.E. Dibb, L.K. Emmons, R.A. Ferrare, C.A. Hostetler, P.B. Russell, H.B. Singh, A.M. Thompson, G.E. Shaw, E. McCauley, J.R. Pederson, J.A. Fisher, The arctic research of the composition of the troposphere from aircraft and satellites (ARCTAS) mission: design, execution, and first results. Atmos. Chem. Phys. 10, 5191-5212 (2010)
13. X. Xiong, C.D. Barnet, Q. Zhuang, T. Machida, C. Sweeney, P.K. Patra, Mid-upper tropospheric methane in the high Northern Hemisphere: spaceborne observations by AIRS, aircraft, measurements, and model simulations. J. Geophys. Res. 115, D19309 (2010)

14. D. Wunch, G.C. Toon, J.L. Blavier, R.A. Washenfelder, J. Notholt, B.J. Connor, D.W.T. Griffith, V. Sherlock, P.O. Wennberg, The total carbon column observing network. Philos Trans R Soc 369, 2087-2112 (2011)

15. G. Durry, I. Pouchet, A near-infrared diode laser spectrometer for the in situ measurement of methane and water vapor from stratospheric balloons (American Meteorological Society, 2001)

16. P. Werle, Areview of recent advances in semiconductor laser based gas monitors. Spectrochim. Acta Part A 54, 197-236 (1998)

17. M. Lackner, Tunable diode laser absorption spectroscopy (TDLAS) in the process industries-A review. Rev. Chem. Eng. 23, 65-147 (2007)

18. D. Herriot, H. Kogelnik, R. Kompfner, Off-axis paths in spherical mirror interferometers. Appl. Opt. 3(4), 523-526 (1964)

19. G. Durry, G. Megie, In-situ measurements of $\mathrm{H}_{2} \mathrm{O}$ from a stratospheric balloon by diode laser direct-differential absorption spectroscopy at $1.39 \mu \mathrm{m}$. Appl. Opt. 39(30), 5601-5608 (2000)

20. J. Fisher, R.R. Gamache, A. Goldman, L.S. Rothman, A. Perrin, Total internal partition sums for molecular species in the 2000 edition of the HITRAN database. J. Quant. Spectrosc. Radiat. Transfer 82, 401-412 (2003)

21. M.G. Allen, Diode laser absorption sensors for gas-dynamic and combustion flows. Meas. Sci. Technol. 9, 545-562 (1998)

22. M. Ghysels, L. Gomez, J. Cousin, N. Amarouche, H. Jost, G. Durry, Spectroscopy of $\mathrm{CH}_{4}$ with a difference-frequency generation laser at 3.3 micron for atmospheric applications. Appl. Phys. B 104, 989-1000 (2011)

23. D.S. Baer, V. Nagali, E.R. Furlong, R.K. Hanson, Scanned- and fixed- wavelength absorption diagnostics for combustion measurements using multiplexed diode lasers. AIAA J. 34(3), 489-493 (1996)

24. M. Ghysels, L. Gomez, J. Cousin, H. Tran, N. Amarouch, A. Engel, I. Levin, G. Durry, Temperature dependences of air-broadening, air-narrowing and line-mixing coefficients of the methane $v_{3} \mathrm{R}(6)$ manifold lines- Application to in situ measurements of atmospheric methane. J. Quant. Spectrosc. Radiat. Transfer 133, 206-216 (2014)

25. H.I. Schiff, G.I. Mackay, J. Bechara, The use of tunable diode laser absorption spectroscopy for atmospheric measurements. Res. Chem. Intermed. 20(3), 525-556 (1994)

26. P.W. Werle, P. Mazzinghi, F. D’Amato, M. De Rosa, K. Maurer, F. Slemr, Signal processing and calibration procedures for in situ diode-laser absorption spectroscopy. Spectrochim. Acta Part A 60, 1685-1705 (2004)

27. P. Werle, R. Mucke, F. Slemr, The limits of signal averaging in atmospheric trace-gas monitoring by tunable diode-laser absorption spectroscopy (TDLAS). Appl. Phys. B 57, 131-139 (1993)

28. H. Chen, J. Winderlich, C. Gerbig, A. Hoefer, C.W. Rella, E.R. Crosson, A.D.V. Pelt, J. Steinbach, O. Kolle, V. Beck, B.C. Daube, E.W. Gottlieb, V.Y. Chow, G.W. Santoni, S.C. Wofsy, High-accuracy continuous airborne measurements of greenhouse gases $\left(\mathrm{CO}_{2}\right.$ and $\mathrm{CH}_{4}$ ) using the cavity ring-down spectroscopy (CRDS) technique. Atmos. Measurement Tech. 3, 375-386 (2010) 